\title{
Technology Development Recommendations of Artificial Intelligence used in Library
}

\author{
https://doi.org/10.3991/ijes.v9i4.25499 \\ Emmanuel Genesius Evan Devara, Teguh Rijanandi(®), Rohman Beny Riyanto \\ Telkom Institute of Technology Purwokerto, Indonesia \\ 19104008@ittelkom-pwt.ac.id
}

\begin{abstract}
The library is a place to read books with various collections so that readers can get various sources of knowledge. But in this technological era, people want things that are more practical. With the presence of Artificial intelligence, it can be applied and integrated into the library system. A common problem when readers come to the library is to look for literature according to their choice, both in terms of the name, image, type, and form of the literature. Artificial intelligence can help in searching literature based on recommendations and ratings, so readers don't have to bother looking for the desired literature one by one from the available bookshelves. This certainly makes it easier for readers to search for literature, especially those who are confused about where to look. The recommendation system used is the recommendation method, where the method is a method that combines Filtering and Ranking. This research is intended so that readers who are in the library can easily and quickly search for their literature.
\end{abstract}

Keywords—artificial intelligence, recommendations, libraries, literature

\section{Introduction}

Library Manuals are not the time anymore, searching for books manually in libraries will soon pass because there are many emerging information technology applications that can help librarians' performance become much simpler and easier, namely with artificial intelligence (AI). Artificial intelligence is an artificial intelligence that is integrated with the system, the technical work of the AI system in this library is that it can automatically recommend literature based on keywords and someone's rating.

Currently, there have been many developments of artificial intelligence that resembles human intelligence so that it can replace the role of librarians in carrying out performance in the library. The use of Artificial intelligence serves to assist librarians in carrying out librarian activities, with the presence of Artificial intelligence, it can be used as a solution for librarians to optimally serve users without leaving their job as information managers in the library.

With the presence of this recommendation system, it can really help potential readers who are confused because of the many types and choices of literacy available. This system will provide prospective readers with literacy recommendations in accordance with the categories provided, so that readers no longer have difficulty in searching for literacy on the bookshelf one by one. 
The development of information and communication technology is currently growing rapidly thus providing many positive impacts on various human activities which in the end demands librarians to continue to adapt even balance between services and the needs of library users. The role of information technology today is of course very important for library management which will have a very large influence on people's lives today. Adjustment of information and communication technology can have an influence on the use of libraries effectively and efficiently [1]. Information and communication technology can be said to help support the process of managing librarians in the library. Information technology in the era of the industrial revolution 4.0 calls for librarians to collaborate and communicate well so that they can be automated into a system [1]. In its application in libraries, information technology can be seen from the use of software and hardware.

Artificial intelligence can be used as a strategy for library managers to promote services and facilities that later will be present and then given to library users to facilitate the process of searching for books. With the emergence of Artificial intelligence, librarians can focus on serving users according to the flow and policies agreed upon by the library so that Artificial intelligence can become a librarian's virtual world partner in providing one-stop service to library users. This collaboration can give an interesting impression to users when they know the sophistication of librarians who are able to read and translate user needs according to the specialist subject that has been determined.

Indeed, to bring artificial intelligence in this library is not as easy as turning the palm of the hand, it takes a lot of knowledge, insight and of course also costs that are not small. But if successful, the library will become a center of knowledge and insight that is not boring, even libraries can also be present online in cyberspace.

\section{Research methodology}

In this research using the recommendation method, where this system uses collaborative filtering and content based filtering. Where both methods are commonly found in recommendation systems [3].

The type of data that will be used in the research is qualitative data, and the data sources that will be used are primary data and secondary data. Primary data were obtained from field surveys, while secondary data were obtained from various publication sources. The analytical method used is a descriptive approach [4].

\subsection{Dataset}

This study uses the book recommendation dataset, which was obtained from the website of https://www.kaggle.com/arashnic/book-recommendation-dataset. The data that is analyzed and used in this study is in the form of a csv file which contains book data.

\subsection{Collaborative filtering}

Collaborative Filtering $(C F)$ is one of 2 ways of recommendation that is the basis for assessing recommendations based on rating values, in short this method uses the 
opinions of other users to give preference to other users as well. This technique has been widely used in various applications such as Amazon.com.

\subsection{Content based filtering}

Content-based Filtering provides recommended articles that are slightly similar to items previously liked by users. The basic principles of this Content-based filtering system are: 1) To analyze the description of the items favored by the user in order to determine the main general attributes (preferences) that will be used to distinguish these items. 2) To compare the attributes of each item with the user profile so that only items that have a high acidity level with the user profile will be recommended. Application of the technique. [6]

Data obtained from electronic sources (internet) and so on which are related to this research and then we store them in a database. So, research will be carried out in a library to obtain data that will later be used as a method in making this AI.

In the application of artificial intelligence this is the first step, namely machine learning, AI knows the number of data collections entered by the user, starting from the title/book number/image which will later enter the database and for images, AI can detect it correctly based on data input, so as to find the appropriate literature. The following is Flowchart of artificial system intelligence in the library can be seen in Figure 1.

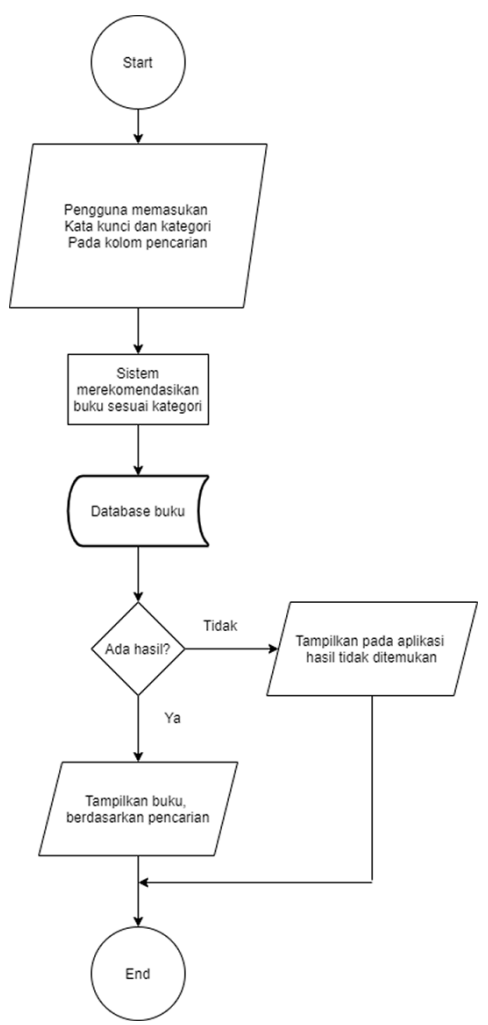

Fig. 1. Flowchart of artificial intelligent in the library 
Judging from the flowchart above, it can be explained that AI works starting from when the user enters a book category using keywords (codes) that have been provided by the librarian to facilitate the book search process, after the librarian enters the code into the system, a book that matches the code entered will appear. However, if the book has not been registered into the system but there is already a code, then when the librarian enters the code into the system, no results will appear. So, librarians must ensure that each book and its code has been registered in the AI system used by librarian.

\section{Discussion result}

Based on the dataset owned, namely the number of book titles as much as 240,000 data, with the amount of data counted, the results stated will be more accurate.

\subsection{Results}

\begin{tabular}{|c|c|c|c|c|c|c|}
\hline & Book-Title & Book-Author & mean & count & weighted rating & Year-of-Publication \\
\hline 0 & Harry Potter and the Goblet of Fire (Book 4) & J. K. Rowling & 6.541237 & 194 & 5.985285 & 2000 \\
\hline 1 & Harry Potter and the Chamber of Secrets (Book 2) & J. K. Rowling & 6.611765 & 170 & 5.978717 & 1999 \\
\hline 2 & Free & Paul Vincent & 7.962963 & 54 & 5.973507 & 2003 \\
\hline 3 & Harry Potter and the Prisoner of Azkaban (Book 3) & J. K. Rowling & 6.467005 & 197 & 5.929681 & 1999 \\
\hline 4 & Harry Potter and the Sorcerer's Stone (Book 1) & J. K. Rowling & 6.363095 & 168 & 5.767724 & 1998 \\
\hline 5 & Harry Potter and the Order of the Phoenix (Boo... & J. K. Rowling & 5.571856 & 334 & 5.320583 & 2003 \\
\hline 6 & The Fellowship of the Ring (The Lord of the Ri... & J. R. R. Tolkien & 6.206349 & 63 & 5.036522 & 1999 \\
\hline 7 & Griffin \&amp; Sabine: An Extraordinary Corresp... & Nick Bantock & 6.041667 & 72 & 5.024219 & 1991 \\
\hline 9 & Falling Up & Shel Silverstein & 6.921053 & 38 & 5.008320 & 1996 \\
\hline 10 & The Stand (The Complete and Uncut Edition) & Stephen King & 6.175439 & 57 & 4.942104 & 1990 \\
\hline 11 & Ender's Game (Ender Wiggins Saga (Paperback)) & Orson Scott Card & 5.302564 & 195 & 4.942059 & 1994 \\
\hline 12 & The Little Prince & Antoine de Saint-ExupĀ̄ry & 5.797468 & 79 & 4.918397 & 1968 \\
\hline 13 & The Secret Life of Bees & Sue Monk Kidd & 5.500000 & 96 & 4.815270 & 2002 \\
\hline 14 & Harry Potter and the Sorcerer's Stone (Harry P... & J. K. Rowling & 4.900175 & 571 & 4.786846 & 1999 \\
\hline 15 & The Hobbit: The Enchanting Prelude to The Lor... & J.R.R. TOLKIEN & 5.007117 & 281 & 4.777967 & 1986 \\
\hline 17 & To Kill a Mockingbird & Harper Lee & 4.920308 & 389 & 4.756743 & 1988 \\
\hline 18 & The Two Towers (The Lord of the Rings, Part 2) & J.R. R. Tolkien & 6.230769 & 39 & 4.674876 & 1999 \\
\hline
\end{tabular}

Fig. 2. List of top 20 rating book titles 


\begin{tabular}{|c|c|c|c|c|}
\hline & Book-Author & mean & count & weighted rating \\
\hline 0 & J. K. Rowling & 5.411434 & 2134 & 5.263202 \\
\hline 1 & Bill Watterson & 5.498134 & 536 & 4.977312 \\
\hline 2 & J. R. R. Tolkien & 5.265861 & 662 & 4.866023 \\
\hline 3 & Shel Silverstein & 6.273333 & 150 & 4.674607 \\
\hline 4 & Dr. Seuss & 5.168044 & 363 & 4.551501 \\
\hline 5 & Nick Bantock & 5.278810 & 269 & 4.480927 \\
\hline 6 & Harper Lee & 4.932039 & 412 & 4.427841 \\
\hline 7 & J.R.R. TOLKIEN & 4.511224 & 980 & 4.314315 \\
\hline 8 & Neil Gaiman & 4.453074 & 1236 & 4.298602 \\
\hline 9 & Daniel Quinn & 5.012295 & 244 & 4.253716 \\
\hline 10 & George Orwell & 4.568862 & 501 & 4.210602 \\
\hline 11 & Antoine de Saint-ExupÃ@ry & 5.169492 & 177 & 4.178795 \\
\hline 12 & Gary Larson & 4.470389 & 591 & 4.174605 \\
\hline 13 & Mitch Albom & 4.474820 & 556 & 4.163105 \\
\hline 14 & J.D. Salinger & 4.487713 & 529 & 4.160683 \\
\hline 15 & Herge & 5.351724 & 145 & 4.159600 \\
\hline 16 & J.R.R. Tolkien & 4.818533 & 259 & 4.153959 \\
\hline
\end{tabular}

Fig. 3. List of top 20 author ratings

\begin{tabular}{|c|c|c|c|c|c|c|c|}
\hline & ISBN & title & rating & userId & & Book Read & Rated \\
\hline 0 & 0140293248 & The Girls' Guide to Hunting and Fishing & 5.665600 & 35859 & & Fahrenheit 451 & 10 \\
\hline 1 & 0446612545 & The Beach House & 4.906809 & 35859 & Harry Potter and the Sorcerer's & r's Stone (Harry P... & 10 \\
\hline 2 & 0060959037 & Prodigal Summer: A Novel & 4.630792 & 35859 & One for the Money (Stephanie Plur & lum Novels (Pape... & 10 \\
\hline 3 & 0440206154 & Red Dragon & 4.475506 & 35859 & The Red Tent (Be & Bestselling Backlist) & 10 \\
\hline 4 & 0345339703 & The Fellowship of the Ring (The Lord of the Ri... & 3.652609 & 35859 & & Bel Canto: A Novel & 9 \\
\hline 5 & 0060987103 & Wicked: The Life and Times of the Wicked Witch... & 3.483041 & 35859 & The S & Secret Life of Bees & s \\
\hline 6 & 0316769487 & The Catcher in the Rye & 3.086998 & 35859 & Left Behind: A Novel of the Ea & Earth's Last Days ... & 9 \\
\hline 7 & 0440222656 & The Horse Whisperer & 2.994207 & 35859 & & The Joy Luck Club & 8 \\
\hline 8 & 0515131229 & Dance upon the Air (Three Sisters Island Trilogy) & 2.963652 & 35859 & & Two for the Dough & 8 \\
\hline 9 & 0316284955 & White Oleander : A Novel (Oprah's Book Club) & 2.868035 & 35859 & Balzac and the Little Chinese S & Seamstress : AN... & 8 \\
\hline
\end{tabular}

Fig. 4. List of surprise library usage 
The results obtained from Figures 2 and 3 show that the data can be obtained from the filtration process on the rating of books and authors, this helps the reader in searching based on the category he chooses. With this filter method, it is easier for readers and can find recommendations from the existing categories. In addition, this data filter process can also be done using the surprise library in the code to display more concise and neat results.

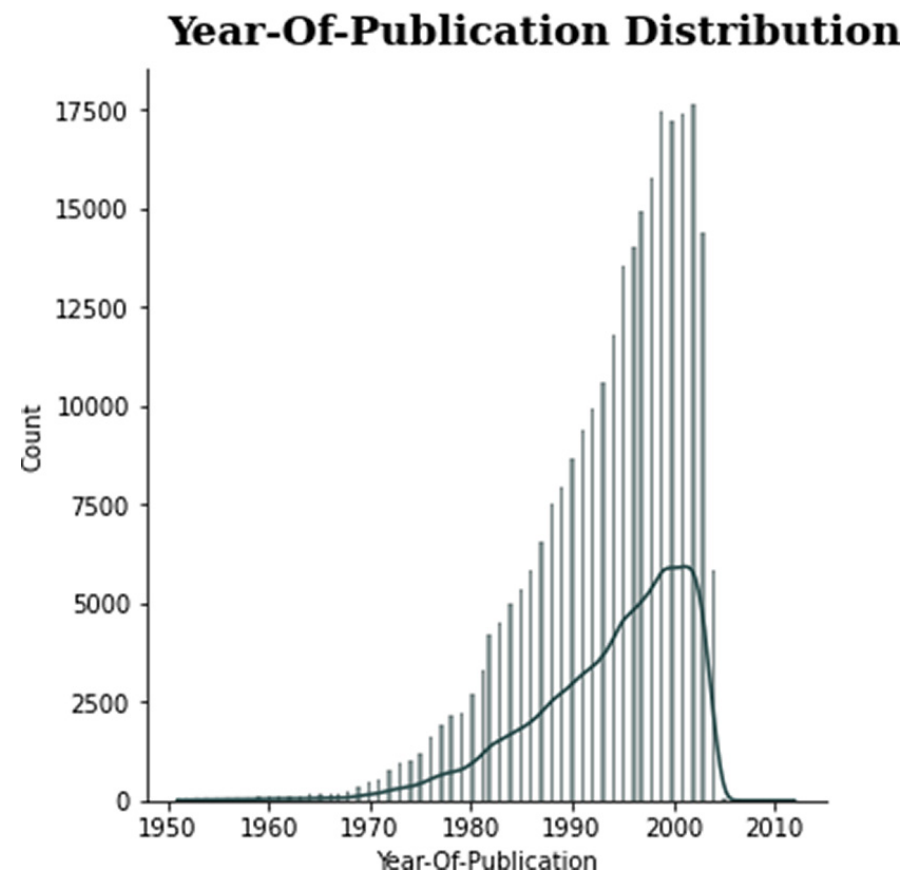

Fig. 5. Graph of distribution of book publications in years

From the graph in Figure 5, it shows that the number of book publications is increasing every year. As time progresses, old books are sometimes increasingly abandoned and therefore, so that the system is not burdened, books from 1950 and earlier will be deleted. This is intended so that there is not too much data in the system and this graph will continue to delete data for books that have low ratings and old publication years.

\subsection{Discussion}

From these results, it can be explained the dataset used along with the database in each table:

Dataset 1 - Rating.csv (11149780)

- User-ID - user ID

- ISBN - book ID

- Book-Rating - Rating given by user 
Dataset 2 - Users.csv (278858)

- User-ID - user ID

- Location - location of user

- Age - age of users

Dataset 3 - Books.csv (271360)

- ISBN - book ID

- Book-Title - Book Name

- Book-Author

- Year-Of-Publication

- Publisher

- Image-URL-S

- Image-URL-M

- Image-URL-L

From the test results, the available book recommendations vary greatly depending on how the keywords and categories are chosen by the user, plus filter factors that can be selected based on the rating of the book title or author. This allows readers to easily choose literacy that is popular and relevant at that time, but a low rating does not mean that literacy is not good, it's just that there are only a small number of people who read and see it. So the system reads the literacy with a low rating.

System rating can also be displayed based on the reader's willingness to seek literacy. From the examples in Figures 2 and 3, it shows the top 20 ranking in the book and its author. This of course can be modified by the reader according to their individual preferences.

\section{Conclusion}

This research provides a solution for book readers, with this research, book readers are facilitated with a technology Artificial Intelligence (AI) to make it easier to find the books they want based on keywords or book categories.

This research uses a machine learning approach and uses the recommendations for collaborative filtering and content based filtering that can search for data by analyzing user input into the database, the system analyzes data that matches user input, if a suitable data is found, the system will display the data to the user.

With this research, it is also easier for someone librarian, because with this research the task of a librarian is reduced because there is already an AI that helps book readers to find the books they want.

\section{$5 \quad$ References}

[1] E. A. Sari, "The Role of Ai Librarians (Artificial Intelligent) as a Promotion Strategy for Higher Education Libraries in the Revolutionary Era 4.0," BIBLIOTIKA J. Kaji. library. and Inf., vol. 3, no. 1, pp. 64-73, 2019, https://doi.org/10.17977/um008v3i12019p064 
[2] A. O. P. Dewi, "Artificial Intelligence as a New Concept in Libraries," Anuva, vol. 4, no. 4, 2020.

[3] A. L. Sembiring, "Qualitative research methods."

[4] E. S. Hamid, and Y. S. Susilo, "Small and medium micro business development strategies in the province of the special region of yogyakarta," 2011. [Online]. Available: www.bps.go.id.

[5] M. Iqbal Fathurrahman, D. Nurjanah, and R. Rismala, "A Recommendation System for Books Using the Trust-Aware Recommendation Recommendation System for books by using the Trust-Aware Recommendation Method."

\section{Authors}

Emmanuel Genesius Evan Devara, S1 Software Engineering Study Program, Faculty of Informatics, Telkom Institute of Technology Purwokerto, Indonesia. Email: 19104005@ittelkom-pwt.ac.id

Teguh Rijanandi, S1 Software Engineering Study Program, Faculty of Informatics, Telkom Institute of Technology Purwokerto, Indonesia. E-mail: 19104008@, ittelkom-pwt.ac.id

Rohman Beny Riyanto, S1 Software Engineering Study Program, Faculty of Informatics, Telkom Institute of Technology Purwokerto, Indonesia. E-mail: 19104060@, ittelkom-pwt.ac.id

Article submitted 2021-07-14. Resubmitted 2021-10-10. Final acceptance 2021-10-14. Final version published as submitted by the authors. 